\title{
Princípios da Análise do Comportamento Aplicados à Análise de Jogo
}

\author{
Gustavo Damasceno Moreira ${ }^{1}$ \\ ${ }^{1}$ Universidade Estadual de Londrina, PR, Brasil. \\ Silvia Regina de Souza ${ }^{1}$ \\ ${ }^{1}$ Universidade Estadual de Londrina, PR, Brasil. \\ Verônica Bender Haydu ${ }^{1}$ \\ ${ }^{1}$ Universidade Estadual de Londrina, PR, Brasil.
}

Resumo: O recurso da análise de jogo é frequentemente usado por técnicos, atletas e cientistas do esporte no contexto esportivo, mas esse recurso não inclui a análise funcional dos comportamentos dos jogadores, uma ferramenta comum aos analistas do comportamento. O presente estudo visou: (a) apresentar uma síntese de alguns princípios da Análise do Comportamento e caracterizar a análise funcional descritiva do comportamento, (b) caracterizar análise de jogo, (c) fazer uma análise funcional do fundamento pênalti, com base nos princípios da Análise do Comportamento e (d) descrever as possíveis contribuições da associação da análise funcional e da análise de jogo. Para isso, após a apresentação dos princípios básicos da Análise do Comportamento aplicados à análise do pênalti, realizou-se uma análise funcional descritiva da cobrança de pênalti, sob a óptica do goleiro e do cobrador da penalidade. Realizar uma análise funcional do fundamento pênalti permitiu especificar as variáveis que determinam jogadas que têm sucesso e insucesso. A partir disso, sugere-se que os dados produzidos pela análise funcional dos comportamentos podem complementar os produzidos pela análise de jogo para possibilitar o planejamento e a avaliação de intervenções aperfeiçoando o treinamento esportivo.

Palavras-chave: Análise Funcional do Comportamento, Análise de jogo, Psicologia do Esporte, Futebol.

\section{Principles of Behavior Analysis Applied to Match Analysis}

\begin{abstract}
Match analysis in the sporting context has been used by coaches, athletes, and sports scientists, but it doesn't include the functional analysis of players' behaviors, a common tool to behavior analysts. The present study aims to: (a) present a synthesis of some principles of Behavior Analysis and characterize descriptive functional analysis of behavior, (b) characterize match analysis, (c) perform a functional analysis of the penalty, based on the principles of Behavior Analysis and (d) describe the contributions of the association of functional analysis and match analysis. For this, after the presentation of the principles of Behavior Analysis applied to the penalty, a descriptive functional analysis of the penalty kick was performed, from the point of view of the goalkeeper and the penalty taker. A descriptive functional analysis allows to evaluate the variables that determine successful and unsuccessful moves. From this, it is suggested that data produced by the functional analysis can complement those produced by the match analysis to enable the planning and evaluation of interventions improving the sports training.
\end{abstract}

Keywords: Behavior Analysis, Match analysis, Sport Psychology, Soccer. 


\title{
Principios del Análisis de Comportamiento Aplicados al Análisis de Juego
}

\begin{abstract}
Resumen: El recurso de análisis de juego a menudo es utilizado por entrenadores, atletas y científicos del deporte en el contexto deportivo, pero este recurso no incluye el análisis funcional del comportamiento de los jugadores, una herramienta común a los analistas de comportamiento. El objetivo de este estudio fue: (a) presentar una síntesis de algunos principios del Análisis de Comportamiento y caracterizar el análisis funcional descriptivo de comportamiento, (b) caracterizar el análisis de juego, (c) realizar un análisis funcional del penal, basado en los principios del Análisis de Comportamiento y (d) describir las aportaciones de la asociación del análisis funcional y del análisis de juego. Por lo tanto, después de la presentación de los principios básicos del Análisis de Comportamiento aplicado al análisis de los penales, se realizó un análisis descriptivo funcional del penal, desde la perspectiva del portero y del penalizador. Realizar un análisis funcional del fundamento penal nos permitió especificar las variables que determinan jugadas exitosas y no exitosas. A partir de esto, se sugiere que los datos producidos por el análisis funcional de los comportamientos pueden complementar los producidos por el análisis de juego para permitir la planificación y evaluación de intervenciones que mejoren la capacitación deportiva.
\end{abstract}

Palabras clave: Análisis Funcional de Comportamiento, Análisis de juego, Psicología del Deporte, Fútbol.

No contexto esportivo, o recurso da análise de jogos tem sido extensamente investigado em razão de técnicos, atletas e cientistas do esporte reconhecerem sua importância enquanto feedback do desempenho em situação de jogo (Mackenzie \& Cushion, 2013). As primeiras pesquisas que avaliaram o recurso da análise de jogo em contextos de esportes coletivos datam da década de 1960. A partir dos anos 1990, com a criação de sociedades científicas internacionais do esporte, da edição de revistas científicas especializadas e da constituição de departamentos autônomos de investigação em universidades, o tema tem ocupado espaço importante na literatura científica dessa área (Marcelino, Sampaio, \& Mesquita, 2011). Assim, realizar estudos que contribuam para aperfeiçoar esse recurso pode aumentar a possibilidade de ele vir a ser usado como fonte de informação para o planejamento de intervenções.

Análise de jogo pode ser definida, segundo Garganta (2001), como o estudo do jogo a partir da observação do comportamento dos jogadores e das equipes. A expressão mais empregada na literatura para se referir ao estudo do jogo é "análise de jogo" (match analysis). No entanto, podem ser encontradas outras denominações, como "observação do jogo" (game observation) e "análise notacional" (notational analysis). Tais expressões, algumas vezes, referem-se a dife- rentes fases de um mesmo processo, as quais têm início com a observação do jogo para, em seguida, anotar ou registrar as informações pertinentes e, finalmente, analisar os dados do jogo (Garganta, 2001).

Em relação aos métodos usados para estudar o tema, as pesquisas têm sido agrupadas em três níveis: a análise da técnica, a análise da tática e a análise cinemática (Clemente, Couceiro, \& Martins, 2012). A análise da técnica consiste em avaliar como e quantas vezes os jogadores executam as habilidades motoras, tais como, o passe, o chute e o cabeceio (Carling, Williams, \& Reilly, 2005). A análise da tática diz respeito à avaliação de comportamentos individuais, grupais e coletivos. Os comportamentos individuais referem-se aos de resolução de problemas ou processo de tomar decisões em situações de jogo, como decidir entre passar a bola ou driblar, enquanto os grupais se referem aos comportamentos coordenados entre poucos jogadores, como a realização de tabelas e jogadas ensaiadas. Os comportamentos coletivos referem-se àqueles dos jogadores da equipe que ocorrem de modo simultâneo de acordo com as regras preestabelecidas, como o sistema tático da equipe (Greco, 1998). A análise cinemática consiste em avaliações biomecânicas do movimento e pode ser empregada, de acordo com Moura (2011), para: (a) o estudo da técnica, fornecendo informações a res- 
peito da execução motora e da quantificação de ações técnicas; (b) análises quantitativas do desempenho físico, fornecendo informações de trajetória, velocidade e distância percorrida; (c) análises da tática que, por meio do registro da posição dos jogadores no campo em função do tempo, fornecem informações táticas individuais, grupais e coletivas, representando as estratégias de jogadores e de equipes.

Os três níveis de análise evoluíram de procedimentos manuais de notação para análise de vídeo computadorizado. Mais recentemente, os estudos têm empregado métodos de avaliação com sistemas de múltiplas câmeras semiautomáticas, sistemas de análise de tempo-movimento baseadas em vídeo (rastreamento ou tracking) e dispositivos de GPS (Sampaio \& Maçãs, 2012). Apesar da evolução tecnológica, essa área de pesquisa mudou muito pouco. Mackenzie e Cushion (2013) apontam que há pouca ou nenhuma evidência recente da aplicação sistemática dos resultados das pesquisas na área de análise de jogo à prática do treinamento. Ressalta-se, contudo, que uma análise de jogo ampliará a elaboração de treinos mais eficazes se houver especificação e descrição das variáveis que facilitam ou dificultam a execução dos comportamentos dos atletas (por exemplo, sucesso e insucesso de jogadas), bem como a discriminação dos estímulos relevantes para execução dos diferentes comportamentos emitidos durante os jogos.

A identificação de variáveis pressupõe a existência de uma teoria da aprendizagem que embase as análises, bem como, as decisões que os treinadores devem tomar, conforme apontaram Ertmer e Newby (1993). A Análise do Comportamento, enquanto uma teoria da aprendizagem, oferece uma gama diversificada de estratégias que podem ser empregadas para aperfeiçoar o desempenho esportivo. De modo direto ou indireto, essas estratégias contribuem para o aperfeiçoamento do recurso de análise de jogo porque descrevem como as interações comportamentais ocorrem em contexto aplicado.

A aproximação da Análise do Comportamento com a área do Esporte é facilitada por fatores relacionados às semelhanças na mensuração dos comportamentos de interesse. A folha de registro de eventos antecedentes e consequentes da resposta utilizada pelo analista do comportamento é semelhante ao scout (instrumento de registro das informações na análise de jogos) usado pelo técnico para avaliar o desempenho de seus atletas (Cillo, 2002). Esse aspecto permite sugerir que descrever brevemente alguns dos princípios da Análise do Comportamento pode ampliar as possibilidades de compreensão das relações comportamentais estabelecidas nos jogos e aperfeiçoar a intervenção, tanto de psicólogos quanto de profissionais do esporte que trabalham nessa área, além de possibilitar o desenvolvimento de pesquisas aplicadas. Assim, os objetivos do presente estudo são: (a) apresentar uma síntese de alguns princípios da Análise do Comportamento e caracterizar a análise funcional descritiva do comportamento, (b) caracterizar análise de jogo, (c) fazer uma análise funcional do fundamento pênalti, sob a ótica do goleiro e do cobrador da penalidade, com base nos princípios da Análise do Comportamento e (d) descrever as possíveis contribuições da associação da análise funcional e da análise de jogo para a eficácia de treinamentos.

\section{Análise do Comportamento e a análise funcional descritiva do comportamento}

A definição de análise de jogo como sendo o estudo do jogo a partir da observação dos comportamentos dos jogadores e das equipes ressalta o comportamento dos jogadores enquanto objeto de estudo (Garganta, 2001). Esse também é o objeto de estudo da Análise do Comportamento, que, de acordo com seus princípios, define o comportamento como sendo a interação do organismo com o ambiente. O organismo altera o ambiente por meio de suas ações e, por sua vez, as alterações ambientais produzidas afetam o organismo que se comporta (Skinner, 1938). Assim, analisar o comportamento implica em investigar esse processo interativo, o que é feito com base no modelo de seleção por consequências.

De acordo com o modelo de seleção por consequências, os comportamentos dos indivíduos e a evolução cultural são explicados por processos de variação e seleção (Skinner, 2007), em analogia ao modelo evolucionista de Charles Darwin. A proposta skinneriana inclui a análise dos comportamentos respondentes e dos comportamentos operantes. O comportamento respondente é aquela relação em que um estímulo ambiental elicia uma resposta reflexa do organismo, como a dilatação e a contração da pupila diante de estímulos luminosos e o suor diante do aumento da temperatura. Pode-se afirmar, conforme Skinner (1953), que de forma geral, o comportamento respondente ocorre na regulação da fisiologia do organismo. 
O comportamento operante, por sua vez, abrange a maior parte das interações de um indivíduo com o ambiente, sendo definido como a relação "entre o que um indivíduo faz e o que acontece no ambiente como consequência de suas ações" (Tourinho, 2003, p. 34). Para esclarecer e representar essa interação, Skinner (1953) propôs que a relação deve sempre especificar três aspectos: (a) o evento que antecede a resposta estímulos antecedentes, (b) a resposta e (c) suas consequências. Esses três elementos formam a unidade básica da análise do comportamento, conhecida como tríplice contingência ou contingência de três termos.

A análise das relações entre os estímulos antecedentes, as respostas e as consequências possibilita inferir relações funcionais entre os eventos ambientais e as respostas do organismo (Matos, 1999). Análises desse tipo são denominadas genericamente avaliações funcionais do comportamento e, especificamente, análises funcionais descritivas e análises funcionais experimentais. Esse último tipo implica no uso de medidas realizadas sob condições de controle e de testagem de variáveis independentes, em que os estímulos antecedentes e as consequências das repostas são arranjadas de tal forma que possam ser estabelecidas as funções desses eventos (Iwata \& Dozier, 2008). A análise funcional descritiva, também designada análise de contingências (Meyer, DelPrette, Zamignani, Banaco, Neno, \& Tourinho, 2010) consiste em observar, descrever e sistematizar as relações de contingências vigentes em um determinado recorte de análise. Com base nos produtos gerados pela análise funcional do comportamento, sugere-se que empregar esse tipo de estratégia para o estudo do comportamento de jogadores pode contribuir para a compreensão das relações entre as ações (repostas operantes) dos jogadores e as variáveis ambientais que as determinam, e aumentar a probabilidade de sucesso, bem como, aperfeiçoar o treinamento, conforme será demonstrado a seguir.

\section{Uma análise funcional de jogo: descrição de cobranças de pênalti}

Para exemplificar a análise funcional descritiva do comportamento, será apresentada uma situação de cobrança de pênalti. Para tanto, é interessante realizar primeiro uma especificação do contexto que envolve uma sequência de cobranças de pênalti, que, por se tratar de um lance particular do jogo, permite um recorte do contexto para uma análise do compor- tamento por dois ângulos, o do batedor e o do goleiro. A situação de cobrança de pênaltis desse exemplo está inserida no contexto de uma final de um campeonato, em que os gols são computados para desempatar uma partida, ou definir o campeão do torneio, sendo o desempate estabelecido pela proporção de gols realizados em relação ao time adversário. Ressalta-se que a sequência de cobranças de pênalti descrita a seguir envolve o jogador (cobrador) de um time de futebol e o goleiro do outro time.

A sequência de cobranças de pênalti considerada para análise consiste em: (a) na primeira cobrança, o jogador chuta a bola rasteira com força e na direção do canto direito, do ponto de vista do cobrador, e tem como consequência o gol; (b) no pênalti seguinte, o jogador chuta alto, no canto esquerdo e com menos força, tendo como consequência a defesa feita pelo goleiro; (c) na próxima cobrança de pênalti, o jogador aumenta a força do chute, modifica a direção da bola um pouco mais para a direita e para o alto, para tirar da direção do goleiro, e a bola vai para fora; (d) na quarta cobrança, o jogador tenta calibrar a força, a altura e a direção de modo que essa nova cobrança se aproxime daquela em que teve como consequência o gol, e faz o gol. Ressalta-se que a análise apresentada é feita em termos probabilísticos já que em uma situação de cobrança de pênalti o goleiro não tem certeza sobre como será feita a cobrança do pênalti (por exemplo, direção e velocidade da bola) e o cobrador não tem certeza sobre qual será o movimento de defesa do goleiro.

Para iniciar a análise funcional descritiva dessa sequência é preciso considerar o comportamento de ambos, goleiro e cobrador, como um processo contínuo inserido em um contexto. O contexto é o campeonato, que além de estabelecer as condições de entrelaçamento de contingências (metacontigências - aspecto que não será abordado no presente artigo devido ao limite de espaço), estabelece operações motivacionais (operações estabelecedoras) que regulam o valor reforçador do resultado do jogo. No processo de interação entre o goleiro e o jogador, alguns comportamentos vão sendo selecionados e passam a ocorrer com maior frequência, enquanto outros vão diminuindo em frequência. Isso se dá porque, quando o indivíduo se comporta em um determinado ambiente, suas respostas operantes são seguidas por consequências que alteram a probabilidade futura dessas repostas voltarem a ser emitidas (Skinner, 
1953). Se as consequências que anteriormente ocorriam após uma resposta deixarem de ocorrer, observa-se o processo de extinção. Para que se observe a extinção, o procedimento deve consistir na retenção do reforço que vinha sendo liberado após a resposta. Esse procedimento leva à diminuição da probabilidade futura da resposta. No caso do exemplo de cobrança de pênaltis, observa-se que o jogador não chuta mais a bola na direção que não levou à realização do gol, caracterizando a extinção daquela topografia e magnitude de resposta (resposta de chutar com a mesma força e direção). Consequências que aumentam a probabilidade futura do comportamento são denominadas "estímulos reforçadores" e o processo "reforço". Consequências que diminuem a probabilidade de determinadas respostas são denominadas "estímulos punitivos" e o processo "punição". Eventos ambientais que estão presentes nas situações em que ocorre o reforço diferencial ou a punição diferencial adquirem funções discriminativas, podendo-se constatar, conforme descrito por Skinner (1953), o estabelecimento do controle de estímulos.

A expressão "controle de estímulos" inclui os conceitos de discriminação e de generalização de estímulos. A generalização de estímulos é observada em situações nas quais uma reposta que foi reforçada na presença de um determinado estímulo passa a ocorrer na presença de estímulos semelhantes àquele que estava presente quando a resposta foi reforçada. Se o indivíduo responde de maneira semelhante na presença dos dois estímulos, ele está apresentando generalização de estímulos (Skinner, 1953). Por sua vez, a discriminação de estímulos consiste em emitir determinada resposta na presença de um estímulo que estava presente na ocasião do reforço e não emitir essa resposta diante do estímulo em cuja presença a resposta não foi reforçada. Reforçar uma resposta na presença de estímulos específicos e não reforçar ou punir na presença de outros estímulos são procedimentos essenciais para que os comportamentos dos organismos fiquem sob o controle dos estímulos.

Na sequência de pênaltis exemplificada, marcar o gol pode ser considerado reforço, se for observado um aumento na probabilidade daquela topografia e magnitude de resposta. O valor reforçador do gol está relacionado, também, com a história do cobrador, durante a qual o gol pode ter sido emparelhado com eventos como sucesso, dinheiro etc. Assim, pode-se afirmar que o episódio vivido pelo jogador nas sessões de treino com o goleiro influenciará a probabilidade de como ele executará a cobrança no jogo em situações semelhantes. Ressalta-se, contudo, que acertar o chute e fazer o gol depende de treino. Na condição de treino, os comportamentos necessários para a execução dos fundamentos esportivos (chute, marcação, entre outros) são repetidos diversas vezes com o objetivo de modelar e aperfeiçoar a coordenação motora. O processo de modelagem ocorre simultaneamente ao processo de discriminação de estímulos, os quais levam o atleta a acertar a direção do gol e a superar o goleiro.

É válido ressaltar que, mesmo em situações semelhantes, alguns estímulos podem variar. Por exemplo, em uma cobrança de pênalti nova, a bola pode ser diferente, o goleiro pode ser outro, a dimensão do gol pode ser menor ou maior, a condição do gramado pode estar boa ou ruim, as condições climáticas podem ser chuva, frio ou calor, e a cobrança de pênalti pode ser realizada de dia ou de noite. As condições que qualificam a cobrança em relação ao status competitivo também variam, se a cobrança for uma simples brincadeira, um treino, um jogo amistoso ou uma final de campeonato. Além disso, alguns estímulos são relevantes para uma resposta bem-sucedida: para o goleiro, por exemplo, o posicionamento do cobrador da penalidade é um evento importante, enquanto outros, além de não serem relevantes, podem inclusive atrapalhar (por exemplo, o comportamento da torcida vaiando os jogadores). Assim, deve-se considerar que o contexto que envolve uma cobrança de pênalti é composto de diversos estímulos, requerendo discriminações e generalizações de estímulos, e a contingência como um todo sendo afetada pelas operações motivacionais presentes.

Quando o jogador se prepara para a terceira cobrança, a resposta sofre influência do gol da primeira batida e da defesa do goleiro na segunda cobrança. Nesse caso, o goleiro e o canto direito da trave são para o cobrador, estímulos discriminativos que controlam a resposta do jogador. Na terceira cobrança, o jogador volta a chutar na mesma direção do primeiro chute, mas com mais força e direcionado um pouco mais para o alto e para a direita para evitar a defesa do goleiro. A consequência da terceira cobrança, bola para fora, evidencia outro estímulo que passa a influenciar a batida do quarto pênalti, a posição da trave. Pode-se inferir que a resposta emitida na quarta cobrança foi controlada por estímulos discriminativos relevantes para converter uma 
cobrança de pênalti em gol. Ressalta-se que além dos aspectos descritos, os lances que o jogador observou do cobrador adversário e dos gols realizados por ele, as instruções do técnico e de companheiros, de seus familiares sobre como responder nessas situações, podem ter contribuído para estabelecer e modelar o comportamento de cobrar o pênalti.

O episódio descrito nessas quatro cobranças de pênalti, de forma bastante simplificada e resumida, exemplifica as experiências que o cobrador pode ter vivido em situações semelhantes e que podem ter modelado e colocado sob o controle de estímulos seu comportamento de cobrar pênaltis. Mas e o goleiro? Quais contingências podem influenciar seu comportamento na situação de pênalti? Se para o cobrador, o comportamento do goleiro e sua relação com o gol são estímulos discriminativos, do mesmo modo, o comportamento do jogador que executará a cobrança e sua relação com a bola são estímulos discriminativos para o goleiro. Portanto, pode-se afirmar que para o goleiro, características do comportamento do cobrador, tais como, pé dominante, distância da bola, direção do olhar, a forma como ele dá as passadas iniciais e a posição do pé de apoio na hora da cobrança podem indicar a possível direção e força da cobrança. Ele pode escolher um canto baseado nesses estímulos discriminativos e tentar antecipar a cobrança ou aguardar até o instante em que a bola é batida, para então se deslocar de acordo com a força e a direção da bola e tentar fazer a defesa.

$\mathrm{Na}$ análise funcional descritiva da sequência de pênaltis para o goleiro, sofrer o gol pode ser considerado uma consequência punitiva. Tomar um gol pode acabar com as chances de o time ser campeão, além da cobrança da torcida, bronca do treinador ou de outros companheiros da equipe. É importante ressaltar conforme foi feito por Matos (1999), que para afirmar que um evento consequente é punitivo ou reforçador é necessário observar o efeito do evento consequente sobre a frequência do comportamento. Por outro lado, evitar o gol ou o cobrador do pênalti chutar a bola para fora podem ser consideradas consequências reforçadoras, pois podem aumentar a probabilidade de o time vir a ser campeão, além dos reforçadores sociais imediatos (por exemplo, elogios e aplausos) e o bem-estar produzido pela boa defesa. $\mathrm{Na}$ análise do bem-estar produzido pela defesa ou o mal-estar produzido pela não defesa, deve-se considerar os comportamentos emocionais, que envolvem tanto respostas reflexas (a eliciação de condições corporais específicas), quanto respostas operantes, caracterizando-se como um fenômeno complexo.

Numa análise simplificada da cobrança de um pênalti, pode-se afirmar que o goleiro possui um padrão de comportamento que foi selecionado durante sua história em cobranças de pênaltis, em lances de outros goleiros que ele observou em situações semelhantes e orientações de treinadores e outros goleiros. Na primeira cobrança, o comportamento do goleiro foi observar o comportamento do cobrador e sob o controle desses estímulos, escolher um canto do gol para se posicionar e, dessa forma, antecipar o movimento de defesa um pouco antes de o cobrador realizar o chute. Na segunda cobrança, diante do gol sofrido na primeira cobrança, o goleiro, na presença de estímulos semelhantes, altera seu comportamento, optando por esperar a cobrança, ver a direção da bola e tentar fazer a defesa, estratégia que possivelmente obteve sucesso em outras ocasiões. Quando o cobrador se prepara para a segunda cobrança, o goleiro o observa atentamente e espera até o momento em que a bola é chutada para definir como fará a defesa. $\mathrm{O}$ pênalti foi cobrado com menor força e a bola foi direcionada mais para o centro. Como o goleiro decidiu esperar a cobrança para ver a direção da bola e só então se deslocar, ele conseguiu fazer a defesa. Na terceira cobrança, a resposta do goleiro sofre influência do gol sofrido na primeira tentativa e da defesa realizada na segunda cobrança do pênalti. No exemplo, o goleiro optou novamente por observar o cobrador e esperar pela saída da bola. A consequência da terceira cobrança, bola para fora, evidencia outro evento consequente que pode influenciar a estratégia de defesa do quarto pênalti, pois dependendo da força da cobrança, altura e direção que a bola pode atingir, ela pode ir para fora do alcance do goleiro e do gol. No quarto chute ao gol, o goleiro mantém a estratégia de observar o cobrador e esperar, mas como a cobrança foi muito forte e a bola foi alta e direcionada ao canto, quando ele discriminou a direção da bola e iniciou sua movimentação, já não era mais possível realizar a defesa, tendo como consequência o gol sofrido.

As estratégias "antecipar a cobrança" e "esperar a cobrança” são baseadas nas probabilidades de defesa contingentes ao chute do cobrador. É válido ressaltar que em ambas as estratégias há prós e contras. Se o cobrador executar um chute forte no canto esquerdo rente à trave, o goleiro teria maior probabilidade de 
defender se tivesse iniciado os movimentos de defesa um pouco antes de a bola ser chutada e tivesse escolhido o canto esquerdo. Entretanto, se o goleiro "antecipar a cobrança" e escolher o canto esquerdo, mesmo que a bola não seja jogada com tanta força, se ela for direcionada para o centro do gol ou para o canto direito, o goleiro não conseguirá voltar e mudar seu deslocamento a tempo de evitar que a bola entre. Se o cobrador executar um chute forte direcionado um pouco mais para o centro do gol, o goleiro terá maior probabilidade de defesa se aguardar até o instante em que a bola foi batida, o que possibilitaria a ele reconhecer a direção da bola e se deslocar para fazer a defesa. No entanto, se o goleiro "esperar a cobrança" para reconhecer a direção da bola e então se deslocar, não haverá tempo suficiente para ele realizar a defesa, se a bola for chutada com força e direcionada no canto rente à trave. Assim como o comportamento do cobrador sofre influência de sua história com cobranças de pênaltis, o comportamento do goleiro de esperar ou antecipar a cobrança é afetado por sua história com situações de defesas de pênaltis, orientações de treinadores e informações referentes ao padrão de cobrança que possíveis batedores podem apresentar, bem como as demais variáveis contextuais citadas em relação ao comportamento do cobrador dos pênaltis. De acordo com Murgia et al. (2014), membros de comissões técnicas têm estudado vídeos de possíveis cobradores de pênalti da equipe adversária com objetivo de identificar padrões de movimentação, força e direção da cobrança e passam essas informações ao goleiro, visando a elaboração de uma estratégia que aumente a possibilidade de discriminação dos estímulos relevantes para que possa ocorrer a defesa.

Em momentos como a cobrança de pênalti, na qual, após o apito do árbitro, quem toma a iniciativa do lance é o cobrador, o goleiro não tem certeza sobre como o pênalti será cobrado. Do mesmo modo, apesar de iniciar o lance, o cobrador também não sabe como o goleiro se comportará para realizar a defesa. Em relação a isso, Nico (2001) afirma que:

[...] há momentos em que não se sabe quais são as consequências envolvidas, caso o comportamento seja um ou outro. Diante de tal situação, diz-se que o indivíduo toma decisão, manipulando variáveis que aumentam a probabilidade de "escolher" este ou aquele curso de ação. Portanto, o que caracteriza a tomada de decisão é o desconhecimento prévio, por parte do sujeito que se comporta, das consequências a serem produzidas por um e outro comportamento (p. 16).

Com essa afirmação, a autora apresenta o conceito referente ao processo de decidir. Decidir é definido como a emissão de comportamentos de procurar no ambiente pelas variáveis que podem estar relacionadas com as prováveis consequências que podem ocorrer em um ou outro curso de ação, de modo a aumentar a probabilidade de "escolher", isto é, de emitir essa ou aquela resposta (Nico, 2001). Vale ressaltar que decidir não se refere a comportar-se de acordo com o curso de ação escolhido, mas sim emitir comportamentos que produzam informações que auxiliem a decidir (Nico, 2001). Para o goleiro, observar o comportamento do cobrador aumenta a probabilidade da defesa do pênalti. Para o cobrador, olhar para o gol, para a bola e para a posição do goleiro antes de cobrar o pênalti aumenta a probabilidade de que ele emita um chute com a força e direção necessárias para fazer o gol.

Durante o desenvolvimento dessa análise da sequência de cobranças de pênaltis, evidencia-se que o comportamento do cobrador é fonte de estímulos relevante para o comportamento do goleiro, bem como o comportamento do goleiro o é para o cobrador. Pode-se afirmar, portanto, que uma cobrança de pênalti se configura como um episódio social, uma vez que, as variáveis a serem consideradas para um indivíduo são geradas pelo outro indivíduo, conforme definição proposta por Skinner (1953). O episódio social em questão é a competição, na qual “o comportamento de um pode ser reforçado apenas à custa do reforço do outro" (Skinner, 1953, p. 340).

\section{Análise Funcional do Comportamento e Análise de Jogo: uma associação possível para aperfeiçoar a qualidade do treinamento esportivo}

Uma vez tendo sido feita a descrição das relações de contingência entre os eventos antecedentes e consequentes do comportamento de jogadores, como no exemplo anterior (o comportamento do cobrador de chutar a bola com uma determinada força e direção em cada cobrança e do goleiro para tentar realizar a defesa do pênalti), é possível discutir como esse tipo de análise pode ser usada para contribuir para o recurso da análise de jogo. Conforme foi apresen- 
tado anteriormente, pode-se afirmar que os estímulos antecedentes básicos para ambos os jogadores na cobrança de pênaltis são as regras do jogo, o gol (traves e travessão), a bola parada na marca penal e a grande área. Para o cobrador, ainda, o comportamento do goleiro é um estímulo antecedente, assim como o é para o goleiro, o comportamento do jogador que executará a cobrança.

Outras variáveis também podem influenciar o comportamento de ambos os jogadores, como: a categoria da qual a equipe faz parte (profissional, amador, categoria de base); as características do goleiro (habilidade de defender pênaltis, estatura, comportamentos padrões etc.) e as características do cobrador (habilidade em cobrar pênaltis, pé dominante, comportamentos padrões etc.); o placar da partida (perdendo, empatando ou ganhando); o tempo da partida (começo, meio ou fim, do primeiro ou do segundo tempo); o status competitivo (final de campeonato, amistoso ou treino); as condições climáticas; a qualidade do gramado; as instruções do treinador; o dinheiro de um possível bônus por gol marcado ou defesa importante; a possibilidade de artilharia do campeonato por gol marcado ou título de goleiro menos vazado; a comemoração do gol ou da defesa; possíveis problemas particulares; enfim, diversos estímulos podem afetar o comportamento no momento da batida.

Diante do grande número de variáveis que podem influenciar o comportamento de um jogador, identificar aquelas que podem facilitar ou prejudicar a execução do lance é importante. Por exemplo, as variáveis facilitadoras podem aumentar a orientação do jogador aos estímulos adequados do ambiente (Martin, 2001), aumentando as chances de sucesso. É válido ressaltar que, além de se orientar pelos estímulos relevantes, é necessário que o jogador consiga executar toda a cadeia de respostas conforme o planejado. Isso inclui os comportamentos precorrentes, tais como, no caso do cobrador, ajeitar a bola, apoiar o pé, ou seja, todas essas variáveis que podem afetar o desfecho da cobrança de pênalti.

A característica pouco previsível do jogo foi destacada por Garganta (1997, p. 11), que afirmou que ela "tem sido responsável pelas acentuadas dificuldades encontradas sempre que se pretende avaliar o rendimento de um jogador ou de uma equipe". Isso porque, mesmo que o jogador tenha prestado atenção aos estímulos relevantes, decidindo com alta probabilidade de sucesso e acertado a execução motora, ainda assim, ele poderia ter seu desempenho avaliado como negativo se a bola bater na trave e sair ou se o goleiro defender a cobrança. Do mesmo modo, se a bola bater na trave e entrar no gol, o desempenho do jogador cobrador poderia ser avaliado como positivo independentemente da forma como ele decidiu executar a ação ou se a execução motora saiu como planejado.

Analisar o desempenho do cobrador e do goleiro apenas por meio da observação e do registro dos resultados do lance, o que geralmente é feito quando se realiza a análise de jogo, tem como consequência apenas a produção de dados sobre a frequência de conversão em gols do cobrador (dois gols em quatro cobranças) e de defesas do goleiro (uma defesa em quatro cobranças). A avaliação do desempenho pelo resultado obtido (por exemplo, ter feito ou não o gol) pode não oferecer indicadores para orientar o jogador, corrigir erros e maximizar o seu desempenho nesses lances. Por exemplo, o resultado do lance é pouco útil para avaliar em que aspectos o desempenho do cobrador ou do goleiro pode melhorar ao longo da temporada. Os dados obtidos por meio do registro do resultado apenas não oferecem estímulos que o treinador possa discriminar para propor intervenções.

Para que o treinador possa propor intervenções efetivas, outras informações são necessárias. Isso porque, mesmo sendo o conteúdo do jogo multifatorial e de difícil previsão, é necessário identificar e registrar variáveis ou indicadores de qualidade, na medida em que eles funcionam como referências para avaliação do desempenho dos jogadores e elaboração das situações de ensino e treino no futebol (Leitão, 2004). Cillo (2003) ressalta que os indicadores selecionados para a análise de jogo devem direcionar a interpretação dos dados enquanto avaliação do comportamento dos jogadores.

$\mathrm{Na}$ situação do pênalti, todos os dados referentes ao comportamento do goleiro e do cobrador podem ser relacionados com o contexto antecedente em que ocorrem e com as consequências que geram. Ao registrar essas informações ao longo de seguidas cobranças, é possível analisá-las de modo a identificar padrões de comportamento e isso poderia auxiliar os treinadores a modelarem os comportamentos precorrentes, aumentando a probabilidade de sucesso.

Apesar da dificuldade de se especificar quais estímulos realmente afetam o comportamento dos jogadores no momento de decidir e da dificuldade em se avaliar se a execução motora saiu como planejado, ao realizar uma análise funcional do lance é possível: 
(a) avaliar o comportamento do jogador descrevendo adequadamente o seu desempenho (comportamento-alvo) e identificar quais estímulos são relevantes para aumentar a probabilidade de sucesso, (b) estabelecer estratégias que garantam a realização dos mesmos procedimentos de observação e registro do comportamento-alvo ao longo do tempo, (c) observar e comparar padrões de comportamento com o intuito de aumentar a probabilidade de prever respostas diante de determinados contextos, (d) planejar intervenções para melhorar o desempenho do jogador e (e) avaliar a eficácia das intervenções.

\section{Considerações Finais}

O presente estudo definiu a análise de jogo como o estudo do jogo a partir da observação do comportamento dos jogadores e das equipes, conforme proposto por Garganta (2001). Subsequentemente, foram especificados alguns dos princípios da Análise do Comportamento e caracterizou-se a análise funcional descritiva, que estabelece que os comportamentos devam ser analisados considerando os eventos antecedentes, as respostas e as consequências. Em seguida, a análise funcional descritiva foi aplicada a um fundamento do futebol, o pênalti. Por fim, por meio da descrição apresentada, buscou-se identificar algumas variáveis que facilitam ou dificultam a execução desse fundamento, bem como a discriminação dos estímulos relevantes para sua execução.

Defende-se no presente estudo que combinar a análise de jogo e a análise funcional do comportamento fornece ao treinador recursos para intervenções mais efetivas, isso porque, permite a ele não só a observação do comportamento dos jogadores, mas também a discriminação de variáveis relevantes que podem ser manipuladas para aumentar a eficácia dos treinos. Um dos aspectos que se destaca neste artigo é que a análise funcional do comportamento aumenta o grau de previsibilidade das condições de jogo, maximizando o desempenho eficaz dos atletas e, consequentemente, as chances de sucesso. Conclui-se, portanto, que o estudo do jogo a partir da observação do comportamento dos jogadores e das equipes (análise de jogo), bem como, a descrição e sistematização das relações de contingências (análise funcional do comportamento) possibilita a compreensão da função dessas variáveis e permite prever e controlar os comportamentos.

\section{Referências}

Carling, C., Williams, A. M., \& Reilly. T. (2005). Handbook of soccer match analysis: A systematic approach to improving performance. London: Routledge.

Cillo, E. N. P. (2002). Psicologia do esporte: Conceitos aplicados a partir da análise do comportamento. In A. M. S. Teixeira, M. R. B. Assunção, R. R. Starling, \& S. S. Castanheira, (Orgs.), Ciência do comportamento: Conhecer e avançar (pp. 119-137). Santo André, SP: Esetec.

Cillo, E. N. P. (2003). Análise de jogo como fonte de dados para a intervenção em psicologia do esporte. In K. Rubio (Org.), Psicologia do esporte aplicada (pp. 33-54). São Paulo, SP: Casa do Psicólogo.

Clemente, M. F., Couceiro, M. S., \& Martins, F. M. L. (2012). Towards a new method to analyze the soccer teams tactical behaviour: Measuring the effective area of play. Indian Journal of Science and Technology, 5(12), 3792-3801. https://doi.org/10.17485/ijst/2012/v5i12/30615

Ertmer, P. A., \& Newby, T. J. (1993). Behaviorism, cognitivism, constructivism: Comparing critical features from an instructional design perspective. Performance Improvement Quarterly, 6(4), 50-72. https://doi. org/10.1111/j.1937-8327.1993.tb00605.x

Garganta, J. (1997). Modelação tática do jogo de futebol: Estudo da organização da fase ofensiva em equipes de alto rendimento (Tese de doutorado). Universidade do Porto, Porto, Portugal. Recuperado de: https://repositorio-aberto.up.pt/handle/10216/10267

Garganta, J. (2001). A análise da performance nos jogos desportivos: Revisão acerca da análise do jogo. Revista Portuguesa de Ciências do Desporto, 1(1), 57-64. https://doi.org/10.5628/rpcd.01.01.57

Greco, P. J. (1998). Da capacidade de jogo ao treinamento tático: O treinamento tático. In P. J. Greco (Org.), Iniciação Esportiva Universal: Metodologia de iniciação esportiva na escola e no clube (pp. 77-91). Belo Horizonte, MG: Universidade Federal de Minas Gerais. 
Iwata, B. A., \& Dozier, C. L. (2008). Clinical application of functional analysis methodology. Behavior Analysis in Practice, 1(1), 3-9. https://doi.org/10.1007/BF03391714

Leitão, R. A. A. (2004). Futebol: Análises qualitativas e quantitativas para verificação e modulação de padrões e sistemas complexos de jogo (Dissertação de mestrado). Universidade Estadual de Campinas, São Paulo, SP, Brasil. Recuperado de: http://www.reposip.unicamp.br/handle/REPOSIP/274911?locale=pt_BR

Mackenzie, R., \& Cushion, C. (2013). Performance analysis in football: A critical review and implications for future research. Journal of Sports Sciences, 31(6), 639-676. https://doi.org/10.1080/02640414.2012.746720

Marcelino, R., Sampaio, J., \& Mesquita, I. (2011). Investigação centrada na análise do jogo: Da modelação estática à modelação dinâmica. Revista Portuguesa de Ciências do Desporto, 11(1), 481-499.

Martin, G. L. (2001). Consultoria em psicologia do esporte: Orientações práticas em análise do comportamento. Campinas, SP: Instituto de Análise do Comportamento.

Matos, M. A. (1999). Análise funcional do comportamento. Estudos de Psicologia, 16(3), 8-18. https://doi. org/10.1590/S0103-166X1999000300002

Meyer, S. B., Del Prette, G., Zamignani, D. R.; Banaco, R. A., Neno, S., \& Tourinho, E. Z. (2010). Análise do comportamento e terapia analítico-comportamental. In E. Z. Tourinho, S. V. Luna, \& L. A. Vasconcelos (Org.), Análise do comportamento: Investigações históricas, conceituais e aplicadas (pp. 153-174.). São Paulo, SP: Roca.

Moura, F. A. (2011). Análise quantitativa da distribuição de jogadores de futebol em campo durante jogos oficiais (Tese de doutorado). Universidade Estadual de Campinas, SP, Brasil. Recuperado de: http://www.bibliotecadigital.unicamp.br/document/?code $=000837472$

Murgia, M., Sorsa, F, Muroni, A. F., Santoro, I., Prpic, V., Galmontec, A. et al. (2014). Using perceptual home-training to improve anticipation skills of soccer goalkeepers. Psychology of Sport and Exercise, 15(6), 642-648. https://doi. org/10.1016/j.psychsport.2014.07.009

Nico, Y. C. (2001). A contribuição de B. F. Skinner para o ensino do autocontrole como objetivo da educação (Dissertação de mestrado). Pontifícia Universidade Católica de São Paulo, São Paulo, SP, Brasil. Recuperado de: http:// www.sapientia.pucsp.br//tde_busca/arquivo.php?codArquivo=4973

Sampaio, J., \& Maçãs, V. (2012). Measuring tactical behaviour in football. International Journal of Sports Medicine, 33(5), 395-401. https://doi.org/10.1055/s-0031-1301320

Skinner, B. F. (1938). The behavior of organisms. New York, NY: Appleton.

Skinner, B. F. (1953). Science and human behavior. New York, NY: Free Press.

Skinner, B. F. (2007). Seleção por consequências. Revista Brasileira de Terapia Comportamental e Cognitiva, 9(1), 129-137.

Tourinho, E. Z. (2003). A produção de conhecimento em psicologia: A análise do comportamento. Psicologia: Ciência e Profissão, 23(2), 30-41. https://doi.org/10.1590/S1414-98932003000200006

Gustavo Damasceno Moreira

Bacharel em Ciências do Esporte e Mestre em Análise do Comportamento pela Universidade Estadual de Londrina (UEL), Londrina - PR. Brasil.

E-mail: gdamascenom@gmail.com

(iD https://orcid.org/0000-0002-3210-2146

\section{Silvia Regina de Souza}

Doutora em Psicologia Clínica pela Universidade de São Paulo (USP), São Paulo - SP. Brasil. Docente do Departamento de Psicologia Geral e Análise do Comportamento e do Programa de Pós-Graduação em Análise do Comportamento da Universidade Estadual de Londrina (UEL), Londrina - PR. Brasil.

E-mail: ssouza@uel.br

(iD) https://orcid.org/0000-0002-1496-8114 


\section{Verônica Bender Haydu}

Doutora em Psicologia Experimental pela Universidade de São Paulo (USP), São Paulo - SP. Brasil. Docente do Departamento de Psicologia Geral e Análise do Comportamento e do Programa de Pós-Graduação em Análise do Comportamento da Universidade Estadual de Londrina (UEL), Londrina - PR. Brasil.

E-mail: veronicahaydu@gmail.

(iD) http://orcid.org/0000-0002-4522-8338

Endereço para envio de correspondência

Silvia Regina de Souza.

Departamento de Psicologia Geral e Análise do Comportamento/Universidade Estadual de Londrina Rodovia Celso Garcia Cid, PR 445, KM 380. Caixa Postal: 6001. CEP: 86051-990. Londrina - PR. Brasil.

Recebido 28/09/2017

Reformulado 10/05/2019

Aceito 12/08/2019

Received 09/28/2017

Reformulated $05 / 10 / 2019$

Approved 08/12/2019

Recibido 28/09/2017

Reformulado 10/05/2019

Aceptado 12/08/2019

Como citar: Moreira, G. D., Souza, S. R, \& Haydu, V. B. (2019). Princípios da Análise do Comportamento aplicados à análise de jogo. Psicologia: Ciência e Profissão, 39, 1-11. https://doi.org/10.1590/1982-3703003185907

How to cite: Moreira, G. D., Souza, S. R, \& Haydu, V. B. (2019). Principles of Behavior Analysis applied to match analysis. Psicologia: Ciência e Profissão, 39, 1-11. https://doi.org/10.1590/1982-3703003185907

Cómo citar: Moreira, G. D., Souza, S. R, \& Haydu, V. B. (2019). Principios del Análisis de Comportamiento aplicados al análisis de juego. Psicologia: Ciência e Profissão, 39, 1-11. https://doi.org/10.1590/1982-3703003185907 